Boerma, W.G.W., Groenewegen, P.P., Zee, J. van der. General practice in urban and rural Europe: the range of curative services. Social Science \& Medicine: 1998, 47(4), p. 445-453

\begin{tabular}{|l|l|}
\hline $\begin{array}{l}\text { Postprint } \\
\text { Version }\end{array}$ & 1.0 \\
Journal website & $\underline{\text { http://dx.doi.org/10.1016/S0277-9536(98)00074-4 }}$ \\
\hline Pubmed link & $\underline{\text { http://www.ncbi.nlm.nih.gov/pubmed/9680228 }}$ \\
\hline DOI & $10.1016 /$ S0277-9536(98)00074-4 \\
\hline
\end{tabular}

This is a NIVEL certified Post Print, more info at http://www.nivel.eu

\title{
GENERAL PRACTICE IN URBAN AND RURAL EUROPE: THE RANGE OF CURATIVE SERVICES
}

\author{
WIENKE G. W. BOERMA, ${ }^{1 *}$ PETER P. GROENEWEGEN ${ }^{1,2}$ AND JOUKE VAN DER \\ $\mathrm{ZEE} \mathrm{E}^{1,3}$ \\ ${ }^{1}$ NIVEL (Netherlands Institute of Primary Health Care), P.O. Box 1568, 3500 BN Utrecht, \\ The Netherlands, \\ ${ }^{2}$ Department of Sociology and Department of Human Geography, Utrecht University, \\ Utrecht, The Netherlands and \\ ${ }^{3}$ Department of Medical Sociology, Maastricht University, Maastricht, The Netherlands \\ *Author for correspondence.
}

ABSTRACT -- The variation in the range of services provided by general practitioners (GPs) is not only related to personal characteristics and features of the country's health care system but also to the geographical circumstances of the practice location. In conurbations health services are more widely available than in the countryside, where GPs often are the only providers. With highly mobile populations and a plentiful supply of doctors, in cities the prevailing regulations for access and use of ser- vices are more difficult to maintain. It is also more difficult to control access and thus opportunities for inappropriate use are greater. Against this background an international study was conducted on variation in task profiles of GPs, especially focusing on differences between urban and rural practices. In 1993 standardised questionnaires in the national languages were sent to samples of GPs in 30 countries. Various aspects of service provision were measured as well as practice organisation, location of the practice and personal backgrounds of the GP. Completed questionnaires were received from 7,233 respondents, an overall response rate of $47 \%$. Sources of variation have been analysed by using a two-level model. Rural practices provided more comprehensive services regardless of the health care system. Approximately half of the variation was explained by features of a country's health care system. The GP's position at the point of access to health care was strongly associated with the gatekeeper function controlling access to secondary care. In western countries where the GPs were self employed they had greater involvement in technical procedures and chronic disease management. There was a considerable gap between the task profiles of GPs in eastern and western Europe. We found evidence of a reduced gatekeeper role in inner cities in those countries where GPs held this position. GPs with an estimated overrepresentation of socially deprived people and elderly in the practice population reported a wider range of services. Differences also appeared to be related to factors which are largely controlled by the individual doctor, such as level of training and education, availability of equipment and practice sta. The results have important implications for education, policy development and health care planning both in eastern and western Europe. 
Boerma, W.G.W., Groenewegen, P.P., Zee, J. van der. General practice in urban and rural Europe: the range of curative services. Social Science \& Medicine: 1998, 47(4), p. 445-453

\section{INTRODUCTION}

International studies have shown considerable variation between countries in the range of services offered by general practitioners (GPs). The differences have been associated with features of the health care system, such as: the mode of patient access to secondary care (direct or on referral by GPs in a gatekeeper role), remuneration method (fees for items of service, capitation fees or salary) and health care supply characteristics (density of GPs and of specialists) (Sandier, 1989; Crombie et al., 1990; Fleming and Backer, 1992; Delnoij, 1994; Boerma et al., 1997). There is evidence suggesting that the organisation and regulation of health care systems influences the outcome of health care. For instance, primary care based systems with patient choice and GPs acting as gatekeepers to secondary care are associated with lower costs, increased patient satisfaction, improved health status and decreased use of medication (Starfield, 1994; Groenewegen and Delnoij, 1997).

There are also regional differences within countries in the provision of services. In particular, concern has been expressed about acceptable health services in remote rural areas (Politzer et al., 1991; Pathman et al., 1992; Horner et al., 1993; Lucas and Tonnelier, 1995) and in unattractive inner city areas (Hart, 1971; DHSS, 1980; Talbott, 1991; Hastings and Rashid, 1993; Cox, 1994). In the U.K.

and in the Netherlands, indices of deprivation (Jarman, 1983; Van der Velden et al., 1997) are used to define underprivileged areas qualifying GPs for income supplements.

Compared with their rural equivalents, urban populations make more use of social services, home care and specialist care (outpatient and inpatient), even after allowing for socio-economic and demo- graphic differences (Jeangros and Hausser, 1990; Bowling et al., 1991; Haynes, 1991; Nyman et al., 1991; Clark, 1992; Verheij and De Bakker, 1994; ten Zijtho. et al., 1994). A number of studies has suggested higher utilisation of general practitioner services in rural areas (Dor and Holahan, 1990; Jeangros and Hausser, 1990; Haynes, 1991; Eggen et al., 1993), although Dutch studies (Gloerich and Van der Zee, 1992; Verheij et al., 1992) found more frequent contacts of patients with their GPs in cities. It has been suggested that health care utilisation is related to perceived health status, to health related behaviour and to the availability and accessibility of services (Anderson and Newman, 1973; Inwald, 1980; Verheij, 1996). The supply of hospital facilities has been shown to be a major determinant of variation in the number of patients' visits to hospitals and hospital admissions (Sanders, 1988). In the Netherlands the opening of a new hospital in a remote new town resulted in an increase of visits to the outpatient departments and admissions to the hospital (Dopheide et al., 1986).

As regards the scope of services, Fearn (1988) found British rural GPs to be more involved than their urban colleagues in minor surgery and the insertion of intra-uterine contraceptive devices. Several studies have reported higher referral rates by urban GPs (Posthuma and Van der Zee, 1977; Wijkel, 1986; Post et al., 1991; Blancquaert et al., 1992; Fleming and Backer, 1992; Gloerich and Van der Zee, 1992; Verheij et al., 1992), although, at least for the U.K. the evidence is inconclusive (Wilkin and Smith, 1987).

In the Netherlands, Verheij et al. (1992) reported urban GPs initiated more laboratory investigations and undertook less medical procedures than their rural colleagues. Sixma (1996) monitored hospital based emergency services following the opening of a new suburban hospital and reported substitution of services formerly provided by local GPs.

The study reported here, which was funded by the European Commission, concentrates on differences in profiles of services provided by GPs in 30 European countries. The major aim is to examine these profiles in urban and rural communities and to determine where differences are consistent across Europe. The study is based on material gathered in the European Study of Task Profiles of General Practitioners (Boerma et al., 1997). Briefly, participating GPs answered questionnaires detailing aspects of their activities. The questions were arranged in four task areas:

- The GPs role as doctor of first contact with health problems (first contact tasks). 
- Application of minor surgery and medical techniques (procedure tasks).

- The treatment and follow-up of diseases (treatment tasks).

- The GP role in prevention (preventive tasks).

In this study, we have been chiefly concerned with the first three of these task areas examining medical and therapeutic activity. More details on recruitment methods, questionnaire design, analysis and descriptive results have been published else- where (Boerma et al., 1997). This paper aims to describe and explain differences in the range of curative services among GPs working in urban, intermediate and rural areas in the European countries. Specific hypotheses have been formulated in Section 2.

\section{METHODS}

\section{The dependent variables}

A questionnaire was mailed to participating GPs in their own national languages covering the task areas mentioned. General practitioners indicated on a four point scale their opinion of the degree of involvement they were likely to have in dealing with specified problems. Answers ranging from (almost) never, to (almost) always were scored, respectively, 1-4. Average scores per GP were obtained by summing item scores after excluding:

- Individual data sets with less than 75\% completion.

- Questions where, overall, 85\% of the answers were uniformly given as (almost) always or (almost) never.

- Questions where item scores correlated less with total scores than were represented by a correlation coefficient of 0.40 . After these exclusions, the reliability of the remaining scored items was tested by calculating the Cronbach Alpha coefficient (first contact tasks, 0.94; procedure tasks 0.89 ; treatment tasks 0.88 ).

\section{The independent variables}

Independent variables included in the analysis reported here have been grouped as follows:

- Location: classified subjectively by the respondent as inner city, urban or suburban, mixed urban/ rural, rural. (For some analyses, these were consolidated into urban, rural and intermediate.)

- Distance to nearest hospital or outpatient facility (estimated by the respondent).

- GP characteristics: age, gender, time spent on continuing medical education, vocational training.

- Practice characteristics: solo or partnership practice, use of an appointment system, ancillary sta. support, available equipment.

- Practice population adjustment for under/over representation of socially deprived or elderly per- sons as determined by subjective comparison with nationally available data.

- Health care systems: the GP role as gatekeeper to secondary services and his employment status (salaried or self employed) (Boerma et al., 1993).

- European region: East or West (eastern countries including the Baltic States, Poland, Czech Republic, Hungary, Slovenia, Croatia, Romania, Bulgaria and Turkey).

\section{Analysis}

Averaged task profile scores were generated in each country and for each of the parameters examined and these are presented in tabular form.

Sources of variation in the scope of services of GPs are located at two levels: the local level (the GPs and their practices) and the national level (the characteristics of the health care system). To avoid the drawbacks of both aggregation (loss of information) and disaggregation (over-estimating the effects of the higher level variables) the data were analysed using the hierarchical linear model (Jones, 1993; DiPrete and Forristal, 1994) with the MLn software (Woodhouse, 1995). Practice location was not treated as a separate level but as a practice characteristic. Analyses on each of the three identified GP task areas were 
carried out by introducing successively the following independent variables: - GP characteristics and practice characteristics.

- Practice location (urban, rural, intermediate).

- Health care system characteristics (gatekeeping, employment status).

- European region (East or West).

In Tables 1-6 only the final regression equations are given because changes in the regression coefficients with the introduction of each new group of variables were only marginal. Finally, the analyses have been repeated for each of the health care sys- tem characteristics and in each European region. These separate analyses are presented in Tables 4-6 and were carried out to identify possible interactions at national level between these particular characteristics and the other variables. The regression equations have been evaluated by the proportional reduction of variance firstly at national level and secondly, within each country at practice level.

\section{Hypotheses}

The following hypotheses were tested:

- The range of service of GPs in rural practices is wider than in urban practices (and especially in inner cities).

- The profile of GP services is more limited in practices located close to hospitals (independently from the degree of urbanisation of the practice).

- In countries where GPs have a gatekeeper role and thus patient flows are more controlled, the expected difference between urban and rural GPs is smaller.

\section{RESULTS}

Altogether, 7,233 general practitioners from 30 countries participated. In 17 countries more than half of the sampled GPs completed the questionnaire. The representativeness of the GPs was assessed in 21 countries where national data on age and gender were available. In general, female GPs and the youngest and oldest age groups were slightly underrepresented (Boerma et al., 1997).

\section{GP and practice characteristics}

The characteristics of GPs and practices are distributed by location in Table 1. An evaluation of statistically significant differences is reported in the two extreme right hand columns. The number of countries is entered in which the characteristic examined differed significantly from the inter- national average. In eight countries there were more female GPs in urban practices. The proportion of vocationally trained GPs was low in inner city practices. The proportion working in solo practice was greater in rural practices but the use of appoint- ment systems less. More equipment was available in rural practices. Social deprivation was commoner in urban practices.

In the majority of countries examined individually, there were no significant differences in the characteristics of GPs or their practices when com- pared in urban or rural location.

\section{[TABLE 1]}

\section{Task profiles}

Task profiles in the three areas evaluated are described by location in Table 2 using a similar for- mat to that above. Rural general practitioners had a greater role in first contact tasks and there was evidence of a trend with lowest scores in inner city areas. Analysis of each national data set showed higher scores for rural than urban GPs in 23 countries. Rural GPs reported higher scores than their urban counterparts for the procedure tasks, though the highest scores were reported by GPs working in a mixed urban/rural location. Rural GPs also 
reported higher scores in treatment tasks though this was only evident in 12 of the countries considered individually.

\section{[TABLE 2]}

\section{Analyses of the differences}

Variation between GPs was related both to the GP and practice characteristics examined and to features of the health care system. The intra-class correlations showed that $52 \%$ of the variance in first contact tasks and 57\% in procedure tasks were located at the level of the health care system; whereas $79 \%$ of the variance in treatment tasks was located at the level of the GPs and practices (this is not entered in Table 3). Analysis of the characteristics examined is summarised in Table 3 for each task considered. Beta values from the analyses are presented, those significant at the $5 \%$ level are bold.

\section{First contact tasks}

First contact tasks were related to practice location with higher scores and thus a greater role for GPs in rural practices. This trend was similarly evident when the distance between practice and hospital or outpatient facility was examined: GPs more than $5 \mathrm{~km}$ from the hospital reported higher scores. Scores were higher where practice based estimates of socially deprived persons exceeded the national average. The quantity of equipment and availability of ancillary sta. were associated with higher and routine use of an appointment system with lower scores. The age and gender of the GP were not associated with first contact task scores but vocational training and time spent in continuing medical education were positively associated. At national level, there were strong associations between scores and the gatekeeper role for GPs. The countries of western Europe reported higher scores than those in the east. Variance at national level (which was well over half the total variance), was well explained in this analysis accounting for an $81 \%$ reduction in this variance. Variance within countries (which was $48 \%$ of the total variance) was not satisfactorily explained within the model, accounting for a reduction of variance of only $10 \%$ (see Table 3 , the proportional reduction of variance).

\section{[TABLE 3]}

\section{Procedure tasks}

Scores for procedure tasks were higher for rural GPs and for those practicing at greater distance from the nearest hospital. They were lower for inner city GPs. Medical equipment and the avail- ability of ancillary sta. were positively associated. Male GPs and vocationally trained GPs reported higher scores than female GPs and those without vocational training. At national level, western but not eastern countries reported higher scores for procedure tasks. National variance ( $57 \%$ of the total variance) was well explained by the model with a $69 \%$ reduction of this variance. Within countries, the model accounted for $21 \%$ of the variance.

\section{Treatment tasks}

Task scores on treatment of diseases varied with practice location but to a lesser extent than was evident for first contact tasks and for procedure tasks. Higher scores were found in rural areas and among doctors at greater distance from hospital. Inner city GPs reported slightly lower scores than those in other locations. Higher scores were also found where practice based estimates of the elderly were above average and where medical equipment was more plentiful. Younger GPs and female GPs reported lower scores whereas GPs who spent more time in continuing education, reported higher scores. Self-employed GPs reported higher scores than those who were salaried. Most of the variation in treatment task scores occurred at practice level (79\%) rather than at national level but the factors considered in the model did not explain the variance to a high extent. 


\section{Differences between health care systems}

Analyses were also made for sub-groups of countries according to the characteristics of the health care system: the gatekeeping role, the predominant employment status of GPs and the East/ West distinction. These data are presented in Tables 4-6. In all sub-groups of countries, we found that greater distance between practice or hospital outpatient facility was associated with higher scores for first contact tasks. For procedure tasks, the distance effect only occurred in Western countries and where GPs were gatekeepers. The higher scores for first contact tasks were particularly apparent in countries where the GP acted as a gatekeeper and those countries where the GPs were salaried. In countries where GPs were salaried, vocationally trained GPs reported higher scores for first contact tasks and procedure tasks. Increased scores for rural GPs in treatment tasks were only found in those countries where the GPs did not have a gatekeeper function and were self-employed.

There were several differences on analysis by European region. Higher than average numbers of elderly or socially deprived persons were associated with higher scores for first contact tasks in western but not eastern countries and where GPs acted as gatekeepers. Time spent on continuing medical education was associated with higher scores for first contact in western countries where GPs acted as gatekeepers. Vocational training in western countries and countries where GPs were gatekeepers, was not related to scores for procedure tasks. The availability of medical equipment was related to scores for treatment tasks in western countries and those with a gatekeeper role for GPs. Furthermore, in western countries and where GPs were gatekeepers, there was greater involvement in first contact and in treatment tasks where there was an excess of socially deprived or elderly people. There were sharp differences between GPs in East and West Europe in first contact and procedure tasks but not in treatment tasks. The national characteristics of the health care system (especially the gatekeeper role), were associated with first con- tact task scores but not generally with other task scores.

\section{[TABLE 4]}

\section{[TABLE 5]}

\section{[TABLE 6]}

\section{DISCUSSION}

The results strongly support our main hypotheses: the task profiles of GPs differed between urban and rural locations. General practitioners in rural areas have higher scores and therefore a more important role as doctor of first contact with health problems and in the application of medical technical procedures than their colleagues in inner cities. These findings were supported by the trends evident in the four sub-groups of locations considered and were confirmed in the analysis based on distance between practice and hospital or outpatient facility. The distance to the nearest hospital or outpatient clinic, which is obviously related to the urban-rural distinction, is an independent determinant of the GP's task profile. Treatment tasks were much less determined by the geographical location and more by the GP's background and the practice organisation. Our third hypothesis, stating that there is less difference in the task profiles of urban and rural doctors in gatekeeping systems than in non-gate- keeping systems, was not confirmed.

There were, however, other more obvious inter- actions between the system characteristics and the location of the practices. The reduced involvement of inner city GPs in first contact tasks occurred only in western countries where GPs were gate- keepers. The higher involvement in procedure tasks of GPs working at longer distances from a hospital was only 
true in western countries and where GPs are self-employed. The increased involvement of rural GPs in treatment tasks only applied where GPs were not gatekeepers and were selfemployed.

Before commenting further on the results, it is necessary to consider the definition of urban and rural practice and possible limitations in the findings inherent in the questionnaire used and recruitment bias. The concept of urbanisation and the application of defining criteria varies between countries; a feasible international reference point is not available (Pumain et al., 1992). We used a simple classification in five categories which a doctor could set within the context of his own national situation. The relevance of urbanisation in the context of this study is twofold: it refers to differences in both the subjective experience of space and availability of facilities and services. Concerning the subjective component we recognise that what constituted a particular type of location in one country was not necessarily matched by that in another. For this reason, we also used the additional dimension of distance between practice and hospitals.

By definition there is a selection bias where the sample is not truly random or the response imperfect. We are aware of some under-representation of female doctors and suspect we may be over-rep- resented by doctors well-motivated to participate in this type of study. However, these are unlikely to bias substantially the findings with respect to the main topic of the study, differences between urban and rural practices. Age and gender of the GP were minor determinants of differences in task profiles. This points to a particular limitation of this study applying to countries where many GPs are working in group practices as in the U.K. We have applied the person characteristics of an individual doctor to task profiles which relate both to the functioning of the practice and the individual doctor. For doctors in group practices this could lead to an under-estimation of the impact of the personal characteristics of doctors, such as age and gender, on the task pro- file scores. This however has been partly offset by including the type of practice (solo or partnership) in the analyses.

In a widely based study such as this, there is an inevitable skewness in many of the distributions of the variables. It was not possible always to get the ideal balance between urban and rurally located GPs. In analyses undertaken within a country, this meant that on occasions, sometimes what appeared to be a large difference between urban and rural practice, did not achieve statistical significance.

There are also some methodological difficulties when interpreting findings based on association. Does the level of practice equipment, which was almost universally associated with higher scores in all three task areas, lead to more services provided or is it the other way round? It can be difficult to decide whether a variable such as vocational training for general practice should be considered as part of the health care system or as a function of the individual GP.

Notwithstanding all these difficulties, we believe this study has clarified the relation between urban and rural practices and between countries. Differences found between countries were consider- able and in our model we have gone some way towards explaining variation at national level. Variation at practice level within countries, how- ever, remains largely unexplained.

\section{Implications}

Differences between urban and rural GPs exist regardless of the health care system. Does that matter? Our contention is that it does. It is first necessary to recognise the difference in respect of appropriate training for general practice. It could also be argued that those differences must be considered when contractual arrangements and the related remuneration of GPs are determined. Considered the other way round, it could be argued that the formal position of the GP, especially the role as doctor of first contact, might be more closely defined within each national setting. A coordinating position can only be assured if GPs are institutionally placed in the middle of the patient flow in primary care in a gatekeeper role and with patients registered with a GP. 
With all national governments struggling to contain ever increasing health care costs, it is important to know where the boundaries lie for responsibility in first contact care provision. In the U.K. and to a lesser extent in The Netherlands supplementary payments are applied to the capitation system for elderly persons, for GPs working in severely socially deprived areas and for working in remote and sparsely populated areas. Personal preferences and market forces will no doubt exert influence on a doctor to go where employment prospects are greatest and living conditions are favourable but one of the main concepts of "Health for All" (WHO, 1992) concerns the notion of equality of health care pro- vision and access to it. Even though the role of governments in health affairs is diminishing the equal distribution of health care manpower and facilities must be secured in order to prevent a situation in which services are poorest where the need is greatest.

These results and their implications provide a particular challenge for primary care in Eastern Europe where scores for first contact and medical technical procedure tasks were particularly low. A combination of inadequate resources for primary care, poor remuneration, and lack of equipment has led to particularly low morale and poor motivation amongst GPs. This study could in fact provide a method whereby an evolving situation in the development and delivery of primary care could be monitored.

The study also provides an insight into the operation of the gatekeeping function. Our findings suggest that it is less strong in the inner city areas. If the gatekeeping role of GPs is truly associated with good outcomes and reduced health care costs (Starfield, 1994), then it is unlikely that a country with such a system in place would wish to lose it. Consideration has to be given to the infrastructure of practices in the inner city areas, the generally increased mobility of the population and the ability of GPs working in inner city areas (who commonly live outside these areas) to cope with changing patient demand. The establishment of large general practitioner cooperatives and the introduction of out-of-hours primary care services in Denmark and in the U.K. provide one way of retaining a gatekeeper function around the clock within primary care which is likely to be particularly effective in city areas. Decisions about the gatekeeper role itself for GPs, however, have to be considered in the national context.

Acknowledgements -- The national coordinators of the European Study on Task Profiles of General Practitioners are acknowledged for their essential contributions. In addition, the authors thank Peter Spreeuwenberg for his help with data processing and analysis and Dr Douglas Fleming for his comments on an earlier version of this paper. The study has been made possible by funding from the BIOMED1 programme of the European Union (con- tract No. BMH1-CT92-1636).

\section{REFERENCES}

Anderson, R. and Newman, J. F. (1973) Societal and individual determinants of medical care utilization in the United States. Milbank Memorial Fund Quarterly 51, 95-124.

Blancquaert, I. R., Zvagulis, I., Gray-Donald, K. and Pless, I. B. (1992) Referral patterns for children with chronic diseases. Paediatrics 1, 71-74.

Boerma, W. G. W., De Jong, F. A. J. M. and Mulder, P. (1993) Health Care and General Practice across Europe. NIVEL/NHG, Utrecht.

Boerma, W. G. W., Van der Zee, J. and Fleming, D. M. (1997) Service profiles of general practitioners in Europe. British Journal of General Practice 47, 481-486.

Bowling, A., Farquhar, M. and Browne, P. (1991) Use of services in old age: data from three surveys of elderly people. Social Science and Medicine 6, 689-700.

Clark, D. O. (1992) Residence differences in formal and informal long-term care. Gerontologist 2, 227-233.

Cox, J. (1994) Rural general practice (editorial). British Journal of General Practice 44, 388389.

Crombie, D. L., Van der Zee, J. and Backer, P. (1990) The Interface Study. Royal College of General Practitioners, London. 
Boerma, W.G.W., Groenewegen, P.P., Zee, J. van der. General practice in urban and rural Europe: the range of curative services. Social Science \& Medicine: 1998, 47(4), p. 445-453

Delnoij, D. M. J. (1994) Physician Payment Systems and Cost Control. NIVEL, Utrecht. Department of Health and Social Security (1980) Inequalities in Health. DHSS, London. DiPrete, T. A. and Forristal, J. D. (1994) Multilevel models: methods and substance. Annual Review of Sociology 20, 331-357.

Dopheide, P. P., Kersten, T. J., Nijhout, F. P. and Van der Speld, G. D. (1986) Een Ziekenhuis op nieuw land (A Hospital on New Land). NIVEL, Utrecht.

Dor, A. and Holahan, J. (1990) Urban-rural differences in Medicare physician expenditures. Inquiry 27, 307-318.

Eggen, P., Maeland, J. G. and Skjaerven, R. (1993) Use of primary medical care: does place of residence play a role? Scandinavian Journal of Primary Health Care 11, 31-37.

Fearn, R. M. G. (1988) Norfolk general practice: a comparison of rural and urban doctors. Journal of the Royal College of General Practitioners 38, 270-273.

Fleming, D. M. and Backer, P. (1992) The European Study of Referrals from Primary to Secondary Care. Report to the Concerted Action Committee of Health Services Research for the European Community, Occasional Paper 56. The Royal College of General Practitioners, London.

Gloerich, A. B. and Van der Zee, J. (1992) Determinanten van verwijzen door de huisarts naar de tweedelijn (Determinants of referring by GPs to Secondary Care).

NIVEL, Utrecht.

Groenewegen, P. P. and Delnoij, D. M. J. (1997) Wat zou Nederland zijn zonder de huisarts? (What would be the Netherlands without the General Practitioner?). Elsevier/ de Tijdstroom, Utrecht.

Hart, J. T. (1971) The inverse care law. Lancet 1, 405-412.

Hastings, A. and Rashid, A. (1993) General practice in deprived areas: problems and solutions (editorial). British Journal of General Practice 43, 47-48.

Haynes, R. (1991) Inequalities in health and health ser- vices use: evidence from the General Household Survey. Social Science and Medicine 33, 361-368.

Horner, R. D., Samsa, G. P. and Ricketts, T. C. (1993) Preliminary evidence on retention rates of primary care physicians in rural and urban areas. Medical Care 31, 640-648.

Inwald, A. C. (1980) A comparison of self-referred patients to accident and emergency departments between an urban district and a rural district. Journal of the Royal College of General Practitioners 30, 220-223.

Jarman, B. (1983) Identißcation of underprivileged areas. British Medical Journal 286, 17051709.

Jeangros, C. and Hausser, D. (1990) La population con- sultante en milieu ambulatoire. Sozial- und Praeventivmedizin 1, 24-33.

Jones, K. (1993) Everywhere is nowhere: multilevel perspec- tives on the importance of place. University of Portsmouth, Portsmouth.

Lucas, V. and Tonnelier, F. (1995) Distance d'acceÁs aux soins en 1990 (Distance to care in 1990). CREDES, Paris.

Nyman, J. A., Sen, A., Chan, B. Y. and Commins, P. P. (1991) Urban/rural differences in home health patients and services. Gerontologist 31, 457-466.

Pathman, D. E., Konrad, T. R. and Ricketts, T. C. (1992) The comparative retention of National Health Service Corps and other rural physicians. Journal of the American Medical Association 268, 1552-1558.

Politzer, R. M., Harris, D. L., Gaston, M. H. and Mullan, F. (1991) Primary care physician supply and the medically underserved. Journal of the American Medical Association 266, 104-109.

Post, D., Mokkink, H. G. A., Van Ree, C. M. and Gubbels, J. (1991) Verwijzen en voorschrijven in de stad en op het platteland: een onderzoek naar regionale verschillen in medische consumptie in vijf regio's (Referring and prescribing in the city and in the countryside: a study of regional differences in medical consumption in five regions). Tijdschrift voor Sociale Gezondheidszorg 69, 101-106.

Posthuma, B. H. and Van der Zee, J. (1977) Tussen eerste en tweede echelon, Deel I. (Between First and Second Echelon, Part 1). Nederlands Huisartsen Instituut (NHI), Utrecht.

Pumain, D., Saint-Julien, T., Cattan, N. and Rozenblatt, C. (1992) The statistical concept of the town in Europe. European Communities (EUROSTAT), Luxembourg. 
Boerma, W.G.W., Groenewegen, P.P., Zee, J. van der. General practice in urban and rural

Europe: the range of curative services. Social Science \& Medicine: 1998, 47(4), p. 445-453

Sanders, D. (1988) Variations in hospital admission rates: A review of the literature.

Department of Community Medicine and General Practice, University of Oxford, Oxford.

Sandier, S. (1989) Health services utilization and physician income trends. Health Care Financing Review, Annual Supplement, 33-48.

Sixma, H. J. (1996) Hospital or general practice? Results of two experiments limiting the number of self referrals of patients with injuries to hospitals in The Netherlands Journal of Accident and Emergency Medicine 13, 264- 268.

Starfield, B. (1994) Is primary care essential? Lancet 344, 1129-1133.

Talbott, R. J. (1991) Underprivileged areas and health care planning: implications of use of Jarman indicators of urban deprivation. British Medical Journal 302, 383- 386.

Van der Velden, J., Rasch, P. and Reijneveld, S. A. (1997) Identificatie van achterstandsgebieden. Een systematiek voor de verdeling van extra middelen aan huisartsen (Identification of underprivileged areas. A method for resource allocation to general practitioners). Nederlands Tijdschrift voor Geneeskunde 141, 693-697.

Verheij, R. A. and De Bakker, D. (1994) A critical review of the literature on urban-rural differences in health and health services utilization. In Urban Rural Variations in Health and Health Services Utilization: An Annotated Bibliography, eds. Zijtho. et al., NIVEL Bibliography No. 50. NIVEL, Utrecht.

Verheij, R. A., De Bakker, D. H. and Van der Velden, J.

(1992) De huisarts in de grote Stad (The General Practitioner in the big city). NIVEL, Utrecht.

Verheij, R. A. (1996) Explaining urban-rural variations in health: a review of interactions between individual and environment. Social Science and Medicine 42, 923-935.

Wijkel, D. (1986) Lower referral rates for integrated health centres in the Netherlands. Health Policy 6, 185-198.

Wilkin, D. and Smith, A. (1987) Explaining variation in general practitioner referrals to hospital. Family Practice 4, 160-169.

World Health Organisation (1992) Targets for Health for All. The Health Policy for Europe. Summary of the Updated Edition, September 1991. WHO Regional Office for Europe, Copenhagen.

Woodhouse, G. (1995) A Guide to MLn for New Users. Institute of Education, University of London, London.

Ten Zijtho., P., Verheij, R. and De Bakker, D. (1994) Urban rural variations in health and health services utilization: An annotated bibliography, NIVEL Bibliography No. 50. NIVEL, Utrecht. 
Boerma, W.G.W., Groenewegen, P.P., Zee, J. van der. General practice in urban and rural Europe: the range of curative services. Social Science \& Medicine: 1998, 47(4), p. 445-453

TABLES

Table 1. GPs' personal and practice characteristics broken down to degree of urbanisation of the practice location

\begin{tabular}{|c|c|c|c|c|c|c|}
\hline \multirow[b]{2}{*}{ Characteristics } & \multicolumn{2}{|c|}{ Urban general practitioners } & \multicolumn{2}{|c|}{ Rural general practitioners } & \multicolumn{2}{|c|}{$n$ Countries with sign. diff. ${ }^{a}$} \\
\hline & $\begin{array}{l}\text { inner } \\
\text { city }\end{array}$ & $\begin{array}{l}\text { suburbs/ } \\
\text { towns }\end{array}$ & $\begin{array}{l}\text { mixed urban } \\
\text { and rural }\end{array}$ & rural & $\begin{array}{l}\text { urban } \\
\text { higher }\end{array}$ & $\begin{array}{c}\text { rural } \\
\text { higher }\end{array}$ \\
\hline Age (average in yrs) & 43 & 44 & 44 & 43 & 2 & 1 \\
\hline Gender ( $\%$ female GPs) & 51 & 41 & 30 & 26 & 8 & - \\
\hline Vocational training (\% GPs) & 39 & 47 & 51 & 44 & 3 & 2 \\
\hline Hours for keeping up-to-date & 23 & 18 & 18 & 19 & - & 2 \\
\hline Mode of practice (\% solo) & 26 & 32 & 39 & 63 & - & 9 \\
\hline Ancillary staff ( $\%$ with practice assistance) & 91 & 87 & 82 & 82 & 4 & 2 \\
\hline Appointment system for most consultations (\%) & 39 & 49 & 46 & 35 & 9 & - \\
\hline Equipment (number; max. 25) & 9 & 10 & 11 & 10 & 4 & 11 \\
\hline Elderly above average (\%) & 42 & 41 & 39 & 47 & 3 & 4 \\
\hline Deprived persons above average $(\%)$ & 30 & 24 & 17 & 17 & 13 & 3 \\
\hline$N$ & 1738 & 2372 & 1453 & 1657 & & \\
\hline
\end{tabular}

${ }^{\mathrm{a} T \text {-test, } p+0.05 \text {. }}$

Table 2. Scope of GP services in urban and rural practices in Europe

\begin{tabular}{|c|c|c|c|c|c|}
\hline \multirow[b]{2}{*}{ Task dimension ${ }^{\mathrm{a}, \mathrm{b}, \mathrm{c}}$} & \multicolumn{2}{|c|}{ Urban general practitioners } & \multicolumn{2}{|c|}{ Rural general practitioners } & \multirow[b]{2}{*}{$\begin{array}{c}n \text { Countries with } \\
\text { significant difference }\end{array}$} \\
\hline & inner city & $\begin{array}{l}\text { suburbs/ } \\
\text { towns }\end{array}$ & $\begin{array}{c}\text { mixed urban } \\
\text { and rural }\end{array}$ & rural & \\
\hline The first contact with health problems & $2.52(0.78)$ & $2.79(0.72)$ & $3.02(0.61)$ & $3.13(0.60)$ & 23 \\
\hline Application of medical technical procedures & $1.68(0.74)$ & $2.02(0.83)$ & $2.37(0.86)$ & $2.31(0.78)$ & 21 \\
\hline Treatment and follow-up of diseases & $2.46(0.67)$ & $2.61(0.60)$ & $2.72(0.61)$ & $2.78(0.60)$ & 12 \\
\hline$N$ (at least) & 1333 & 2015 & 1255 & 1456 & 30 \\
\hline
\end{tabular}

${ }^{a}$ Possible scores for task dimensions range from 1-4 (1 = (almost) never involved; 4 = (almost) always involved).

bIn brackets: standard deviations.

${ }^{c}$ In each row differences between average scores are significant $(p<0.01)$.

${ }^{\mathrm{d}} T$-test between urban and rural GPs $(p \leq 0.05)$.

Table 3. Two-level regression analysis to account for variation of GPs' involvement in three task dimensions (standardised regression coefficients)

\begin{tabular}{|c|c|c|c|}
\hline Variables & First contact role & Application of techniques & Treatment of diseases \\
\hline & $\begin{array}{l}\text { (I) Local level } \\
\text { Practice location }\end{array}$ & & \\
\hline Distance to nearest hosp/spec. $(1 \geq 5 \mathrm{~km})$ & 0.059 & 0.076 & 0.032 \\
\hline Inner city $(1=$ inner city $)$ & -0.039 & -0.046 & -0.018 \\
\hline Rural area $(1=$ rural $)$ & $\begin{array}{l}\mathbf{0 . 1 4 2} \\
\text { Organization/ } \\
\text { equipment }\end{array}$ & 0.091 & 0.045 \\
\hline Mode of practice $(1=$ solo $)$ & 0.008 & -0.011 & 0.017 \\
\hline Appointment system ( 1 = yes) & -0.026 & 0.004 & 0.028 \\
\hline Ancillary staff (number) & 0.047 & 0.025 & 0.032 \\
\hline Equipment (No. of items) & 0.132 & 0.295 & 0.166 \\
\hline Elderly ( 1 = above average) & 0.018 & -0.003 & 0.072 \\
\hline Deprived persons ( $1=$ above average $)$ & $\begin{array}{l}\mathbf{0 . 0 3 0} \\
\text { GP's background }\end{array}$ & 0.004 & 0.020 \\
\hline Age & -0.006 & 0.014 & -0.103 \\
\hline Gender $(1$ = woman $)$ & -0.006 & -0.097 & -0.078 \\
\hline Keeping up-to-date $(\mathrm{h})$ & 0.034 & 0.009 & 0.062 \\
\hline Vocational training $(1=$ yes $)$ & 0.067 & 0.048 & 0.024 \\
\hline \multicolumn{4}{|l|}{ (II) National level } \\
\hline & $\begin{array}{l}\text { Health system } \\
\text { characteristics }\end{array}$ & & \\
\hline Usual employment status $(1=$ self-employed $)$ & 0.146 & 0.058 & 0.180 \\
\hline Gatekeeping system $(1=$ gatekeeping $)$ & 0.422 & 0.067 & 0.047 \\
\hline \multirow[t]{2}{*}{ East or West $(1=$ West $)$} & 0.247 & 0.263 & 0.028 \\
\hline & $\begin{array}{l}\text { Proportional } \\
\text { reduction of variance }\end{array}$ & & \\
\hline Country level & $81.5 \%$ & $69.2 \%$ & $47.1 \%$ \\
\hline GP level & $10.5 \%$ & $21.3 \%$ & $6.0 \%$ \\
\hline
\end{tabular}

Bold: $p \leq 0.05$ 
Boerma, W.G.W., Groenewegen, P.P., Zee, J. van der. General practice in urban and rural Europe: the range of curative services. Social Science \& Medicine: 1998, 47(4), p. 445-453

Table 4. Two-level regression analysis to account for variation of GPs' involvement as doctors of first contact (standardised regression

\begin{tabular}{|c|c|c|c|c|c|c|c|}
\hline & All & $\begin{array}{l}\text { Non-gate } \\
\text { keeping }\end{array}$ & $\begin{array}{l}\text { Gate- } \\
\text { keeping }\end{array}$ & East & West & Salaried & $\begin{array}{l}\text { Self- } \\
\text { employed }\end{array}$ \\
\hline \multicolumn{8}{|c|}{ (I) Local level } \\
\hline \multicolumn{8}{|c|}{ Practice location } \\
\hline Distance to nearest hosp/spec. $(1 \geq 5 \mathrm{~km})$ & 0.059 & 0.066 & 0.067 & 0.064 & 0.074 & 0.063 & 0.074 \\
\hline Inner city $(1=$ inner city $)$ & -0.039 & -0.020 & -0.077 & -0.023 & -0.047 & -0.042 & -0.012 \\
\hline Rural area $(1=$ rural $)$ & 0.142 & 0.174 & 0.142 & 0.234 & 0.138 & 0.177 & 0.125 \\
\hline \multicolumn{8}{|c|}{ Organization/equipment } \\
\hline Mode of practice $(1=$ solo $)$ & 0.008 & 0.020 & -0.002 & 0.033 & 0.006 & 0.010 & -0.020 \\
\hline Appointment system $(1=$ yes $)$ & -0.026 & 0.010 & -0.055 & -0.028 & -0.028 & -0.027 & -0.018 \\
\hline Ancillary staff (number) & 0.047 & 0.050 & 0.052 & 0.051 & 0.049 & 0.029 & 0.057 \\
\hline Equipment (No. of items) & 0.132 & 0.147 & 0.180 & 0.119 & 0.215 & 0.137 & 0.201 \\
\hline \multicolumn{8}{|c|}{ Practice population } \\
\hline Elderly $(1=$ above average $)$ & 0.018 & -0.012 & 0.071 & 0.000 & 0.040 & 0.039 & -0.008 \\
\hline Deprived persons $(1=$ above average $)$ & 0.030 & 0.021 & 0.053 & -0.028 & 0.060 & 0.013 & 0.048 \\
\hline \multicolumn{8}{|c|}{ GP's background } \\
\hline Age & -0.006 & -0.003 & -0.009 & -0.048 & 0.025 & -0.009 & 0.006 \\
\hline Gender $(1=$ woman $)$ & -0.006 & -0.022 & 0.008 & -0.020 & 0.008 & -0.003 & -0.001 \\
\hline Keeping up-to-date $(\mathrm{h})$ & 0.034 & 0.024 & 0.060 & 0.026 & 0.056 & 0.030 & 0.051 \\
\hline Vocational training $(1=$ yes $)$ & 0.067 & 0.078 & 0.073 & 0.128 & 0.040 & 0.101 & 0.020 \\
\hline \multicolumn{8}{|c|}{$\begin{array}{c}\text { (II) National level } \\
\text { Health system characteristics }\end{array}$} \\
\hline Usual employment status $(1=$ self-employed $)$ & 0.146 & & & & & & \\
\hline Gatekeeping system $(1=$ gatekeeping $)$ & 0.422 & & & & & & \\
\hline East or West $(1=$ West $)$ & 0.247 & & & & & & \\
\hline
\end{tabular}

Table 5. Two-level regression analysis to account for variation in the application of medical techniques (standardised regression coeffi-

\begin{tabular}{|c|c|c|c|c|c|c|c|}
\hline & All & $\begin{array}{l}\text { Non-gate } \\
\text { keeping }\end{array}$ & $\begin{array}{l}\text { Gate- } \\
\text { keeping }\end{array}$ & East & West & Salaried & $\begin{array}{l}\text { Self- } \\
\text { employed }\end{array}$ \\
\hline \multicolumn{8}{|c|}{$\begin{array}{l}\text { (I) Local level } \\
\text { Practice location }\end{array}$} \\
\hline Distance to nearest hosp $/ \mathrm{spec} .(1 \geq 5 \mathrm{~km})$ & 0.076 & 0.025 & 0.035 & 0.022 & 0.037 & 0.023 & 0.048 \\
\hline Inner city $(1=$ inner city $)$ & -0.046 & -0.029 & -0.013 & 0.011 & -0.030 & -0.036 & -0.001 \\
\hline Rural area $(1=$ rural $)$ & 0.091 & 0.017 & 0.032 & 0.035 & 0.013 & 0.028 & 0.010 \\
\hline \multicolumn{8}{|c|}{ Organization/equipment } \\
\hline Mode of practice $(1=$ solo $)$ & -0.011 & -0.066 & -0.021 & -0.013 & -0.062 & -0.042 & -0.027 \\
\hline Appointment system ( 1 = yes $)$ & 0.004 & -0.010 & -0.023 & -0.029 & -0.021 & -0.032 & 0.037 \\
\hline Ancillary staff (number) & 0.025 & 0.002 & 0.020 & -0.030 & 0.013 & -0.013 & 0.006 \\
\hline Equipment (No. of items) & 0.295 & 0.096 & 0.100 & 0.074 & 0.130 & 0.069 & 0.204 \\
\hline \multicolumn{8}{|c|}{ Practice population } \\
\hline Elderly ( 1 = above average) & -0.003 & -0.017 & -0.001 & -0.020 & -0.002 & -0.006 & 0.005 \\
\hline Deprived persons $(1=$ above average $)$ & 0.004 & 0.017 & -0.009 & -0.022 & 0.018 & -0.019 & 0.048 \\
\hline \multicolumn{8}{|c|}{ GP's background } \\
\hline Age & 0.014 & -0.052 & -0.110 & -0.058 & -0.076 & -0.095 & 0.040 \\
\hline Gender $(1=$ woman $)$ & -0.097 & -0.023 & 0.043 & -0.019 & 0.029 & 0.011 & 0.010 \\
\hline Keeping up-to-date (h) & 0.009 & 0.021 & 0.023 & 0.045 & 0.007 & 0.038 & 0.020 \\
\hline Vocational training $(1=$ yes $)$ & 0.048 & 0.061 & 0.028 & 0.077 & 0.014 & 0.045 & 0.021 \\
\hline \multicolumn{8}{|c|}{$\begin{array}{c}\text { (II) National level } \\
\text { Health system characteristics }\end{array}$} \\
\hline Usual employment status $(1=$ self-employed $)$ & 0.058 & & & & & & \\
\hline Gatekeeping system $(1=$ gatekeeping $)$ & 0.067 & & & & & & \\
\hline East or West $(1=$ West $)$ & 0.263 & & & & & & \\
\hline
\end{tabular}


Boerma, W.G.W., Groenewegen, P.P., Zee, J. van der. General practice in urban and rural Europe: the range of curative services. Social Science \& Medicine: 1998, 47(4), p. 445-453

Table 6. Two-level regression analysis to account for variation in the follow-up and treatment of selected diseases (standardised regression coefficients)

\begin{tabular}{|c|c|c|c|c|c|c|c|}
\hline & All & $\begin{array}{l}\text { Non-gate } \\
\text { keeping }\end{array}$ & $\begin{array}{l}\text { Gate- } \\
\text { keeping }\end{array}$ & East & West & Salaried & $\begin{array}{c}\text { Self- } \\
\text { employed }\end{array}$ \\
\hline \multicolumn{8}{|c|}{ (I) Local level } \\
\hline Distance to nearest hosp $/ \mathrm{spec} .(1 \geq 5 \mathrm{~km})$ & 0.032 & -0.026 & 0.001 & -0.031 & -0.008 & -0.011 & -0.017 \\
\hline Inner city $(1=$ inner city $)$ & -0.018 & -0.007 & -0.010 & -0.031 & -0.001 & -0.029 & 0.025 \\
\hline Rural area $(1=$ rural $)$ & 0.045 & 0.058 & 0.026 & 0.050 & 0.039 & 0.030 & 0.060 \\
\hline \multicolumn{8}{|c|}{ Organization/equipment } \\
\hline Mode of practice $(1=$ solo $)$ & 0.017 & 0.025 & -0.024 & 0.019 & 0.005 & 0.009 & -0.015 \\
\hline Appointment system ( 1 = yes $)$ & 0.028 & -0.017 & -0.012 & 0.010 & 0.030 & 0.004 & -0.048 \\
\hline Ancillary staff (number) & 0.032 & -0.017 & -0.013 & -0.092 & 0.000 & -0.044 & 0.014 \\
\hline Equipment (No. of items) & 0.166 & 0.037 & 0.052 & 0.033 & 0.048 & 0.037 & 0.051 \\
\hline \multicolumn{8}{|c|}{ Practice population } \\
\hline Elderly $(1=$ above average $)$ & 0.072 & -0.016 & 0.051 & 0.010 & 0.027 & 0.002 & 0.037 \\
\hline Deprived persons $(1=$ above average $)$ & 0.020 & -0.014 & -0.014 & 0.028 & -0.007 & 0.019 & -0.008 \\
\hline \multicolumn{8}{|c|}{ GP's background } \\
\hline Age & -0.103 & -0.098 & -0.098 & -0.081 & -0.091 & -0.086 & -0.099 \\
\hline Gender $(1$ = woman $)$ & -0.078 & 0.021 & 0.051 & 0.027 & 0.034 & 0.041 & 0.020 \\
\hline Keeping up-to-date $(\mathrm{h})$ & 0.062 & 0.021 & 0.027 & 0.002 & 0.042 & 0.026 & 0.025 \\
\hline Vocational training $(1=$ yes $)$ & 0.024 & 0.030 & 0.008 & 0.048 & 0.004 & 0.020 & 0.013 \\
\hline \multicolumn{8}{|c|}{$\begin{array}{c}\text { (II) National level } \\
\text { Health system characteristics }\end{array}$} \\
\hline Usual employment status $(1=$ self-employed $)$ & 0.180 & & & & & & \\
\hline Gatekeeping system $(1=$ gatekeeping $)$ & 0.047 & & & & & & \\
\hline East or West $(1=$ West $)$ & 0.028 & & & & & & \\
\hline
\end{tabular}

